\title{
Living donor liver transplantation for diffuse biliary papillomatosis with malignant change: A case report with 10-year follow-up
}

\author{
Jin Uk Choi, Shin Hwang, Dong-Hwan Jung, Gil-Chun Park, Chul-Soo Ahn, \\ Ki-Hun Kim, Deok-Bog Moon, Tae-Yong Ha, Gi-Won Song, and Sung-Gyu Lee
}

\author{
Division of Hepatobiliary Surgery and Liver Transplantation, Department of Surgery, Asan Medical Center, \\ University of Ulsan College of Medicine, Seoul, Korea
}

\begin{abstract}
Biliary papillomatosis is a rare disease of the biliary tract. In this study, we present a case of a male patient with biliary papillomatosis with malignant change who underwent living donor liver transplantation (LDLT). The 49-year-old man was admitted due to intrahepatic ductal mass, which was finally diagnosed as biliary papillomatosis. It was initially treated by photodynamic therapy, but LDLT was planned due to low efficacy of photodynamic therapy. LDLT was performed with a right liver graft from his son. The pathology report revealed intraductal papillary neoplasm with associated invasive carcinoma. He recovered uneventfully. Although the distal bile duct resection margin was free of tumor, the risk of tumor recurrence at the remnant intrahepatic bile duct still remained. Therefore, staged pylorus-preserving pancreatoduodenectomy was planned. However, after 3 months, he was readmitted due to retropancreatic abscess. It took 6 months to control the intractable retropancreatic abscess. Due to late development of retropancreatic abscess and its slow recovery, staged pancreatoduodenectomy was no longer considered. The patient recovered complete at 1 year posttransplant without any evidence of disease recurrence. After 5 years posttransplant, lung metastasis developed and pulmonary metastasectomy was performed three times. No further recurrence developed during the last 3 years to date, and the patient currently is alive, 10 years after the LDLT. Experience on our case and literature review suggest that patients with biliary papillomatosis with or without malignant transformation are selectively indicated for liver transplantation. (Ann Hepatobiliary Pancreat Surg 2020;24:209-215)
\end{abstract}

Key Words: Biliary papillomatosis; Intraductal papillary neoplasm; Living donor liver transplantation; Lung metastasis

\section{INTRODUCTION}

Biliary papillomatosis is a rare disease of the biliary tract with over 200 reported cases in literature. ${ }^{1,2}$ This disease entity is characterized by multiple papillary tumors of both intrahepatic and extrahepatic bile ducts, with clinical features such as abdominal pain, jaundice, and relapsing episodes of cholangitis, due to biliary tract occlusion by biliary stones, mucous plugs, tumor detritus, and blood clots. $^{3}$ Recurrent superinfections of the biliary tract can lead to secondary biliary cirrhosis, which further leads to liver failure. ${ }^{4-7}$

Biliary papillomatosis has two unique features: the widespread pattern along the biliary tract, which is responsible for high rates of recurrence after resection; and the like- lihood of malignant transformation. ${ }^{8}$ Accordingly, complete resection of the whole biliary tree is needed to cure this disease.

We herein present a case of a male patient with biliary papillomatosis with malignant change who underwent living donor liver transplantation (LDLT) and is still alive for 10 years despite lung metastasis.

\section{CASE}

A 49-year-old man was admitted with intrahepatic ductal mass suggesting intrahepatic cholangiocarcinoma. His liver function was normal without jaundice. Tests for hepatitis $\mathrm{B}$ and $\mathrm{C}$ virus were negative. Dynamic computed tomography $(\mathrm{CT})$ scan and magnetic resonance pancreato-

Received: March 11, 2020; Revised: March 13, 2020; Accepted: March 15, 2020

Corresponding author: Shin Hwang

Department of Surgery, Asan Medical Center, University of Ulsan College of Medicine, 88 Olympic-ro 43-gil, Songpa-gu, Seoul 05505, Korea Tel: +82-2-3010-3930, Fax: +82-2-3010-6701, E-mail: shwang@amc.seoul.kr

Copyright (C) 2020 by The Korean Association of Hepato-Biliary-Pancreatic Surgery

This is an Open Access article distributed under the terms of the Creative Commons Attribution Non-Commercial License (http://creativecommons.org/ licenses/by-nc/4.0) which permits unrestricted non-commercial use, distribution, and reproduction in any medium, provided the original work is properly cited. Annals of Hepato-Biliary-Pancreatic Surgery • pISSN: 2508-5778 - elSSN: 2508-5859 
cholangiography showed radiological findings comparable to diffuse intraductal papillomatosis (Fig. 1).

Percutaneous transhepatic biliary drainage (PTBD) catheter was inserted (Fig. 2A) and percutaneous transhepatic cholangioscopy (PTCS) was performed for tissue biopsy (Fig. 2B). The lumens of the whole intrahepatic ducts were covered with villotubular adenomas with focal high-grade dysplasia (Fig. 3A). Some areas showed atypical villous proliferation, which was consistent with well-differentiated adenocarcinoma (Fig. 3B).

To treat biliary papillomatosis, photodynamic therapy had been performed, however, unsatisfactory outcomes were anticipated due to diffuse involvement of the whole intrahepatic bile ducts (Fig. 4). Thus, LDLT using his son's liver graft was planned.

At 10 days after photodynamic therapy, LDLT oper- ation was performed using a modified right liver graft. After examination of the whole abdomen, the distal bile duct was dissected and transected at the upper margin of the pancreas. Intraoperative frozen-section biopsy of the distal common bile duct resection margin was free from disease. The standardized surgical procedures were applied to LDLT operation using a modified right liver graft with a graft-recipient weight ratio of 1.2. Since the common bile duct was resected, Roux-en-Y hepaticojejunostomy was performed for biliary reconstruction. The patient recovered uneventfully and was discharged 3 weeks after the LDLT operation (Fig. 5).

The pathology report of the explant liver specimens revealed the following: intraductal papillary neoplasms with an associated invasive carcinoma that invaded to the subepithelial connective tissue; no involvement of the liver
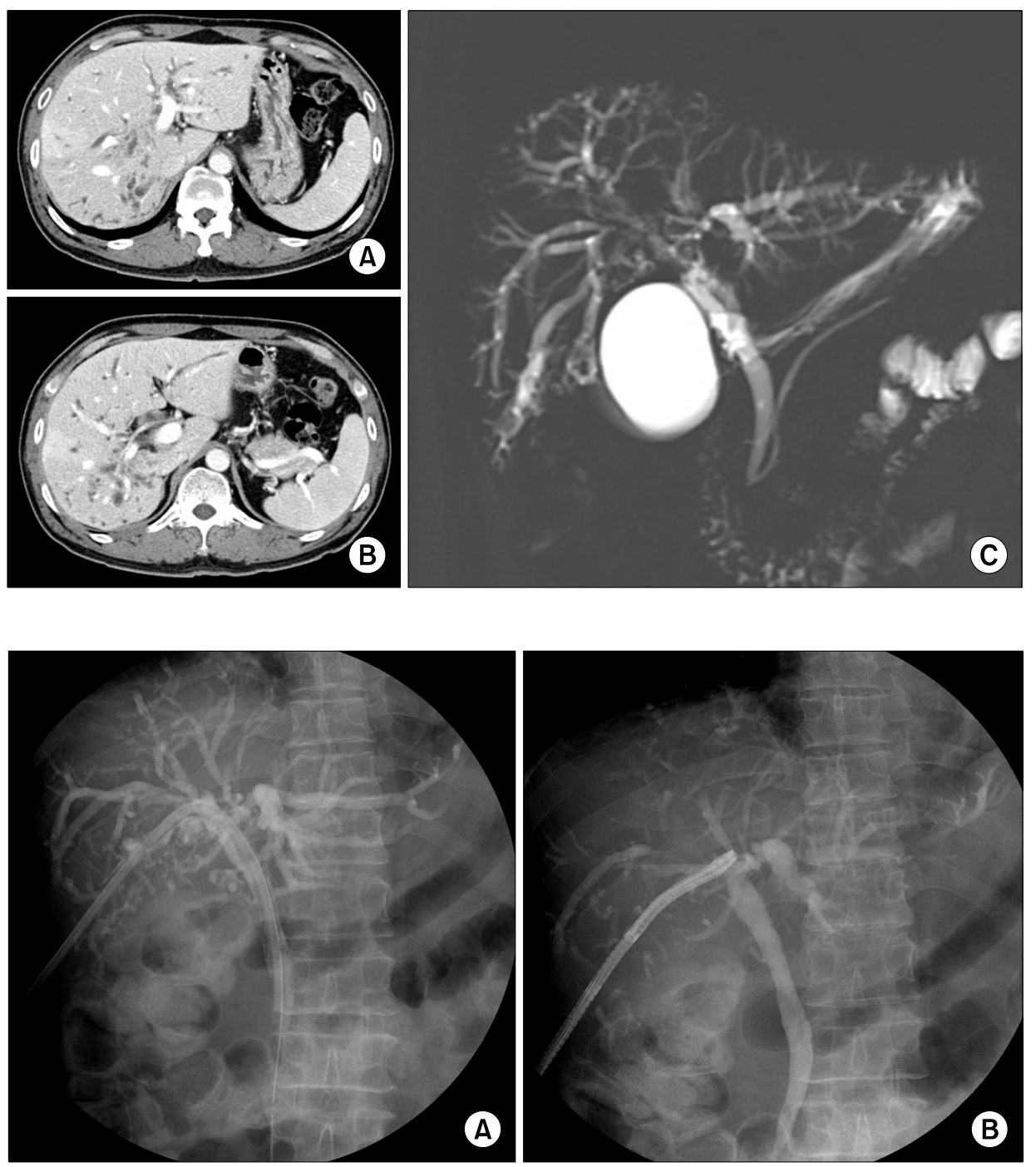

Fig. 2. Cholangiography findings. A percutaneous transhepatic biliary drainage catheter was inserted (A) and percutaneous transhepatic cholangioscopy was performed (B). 

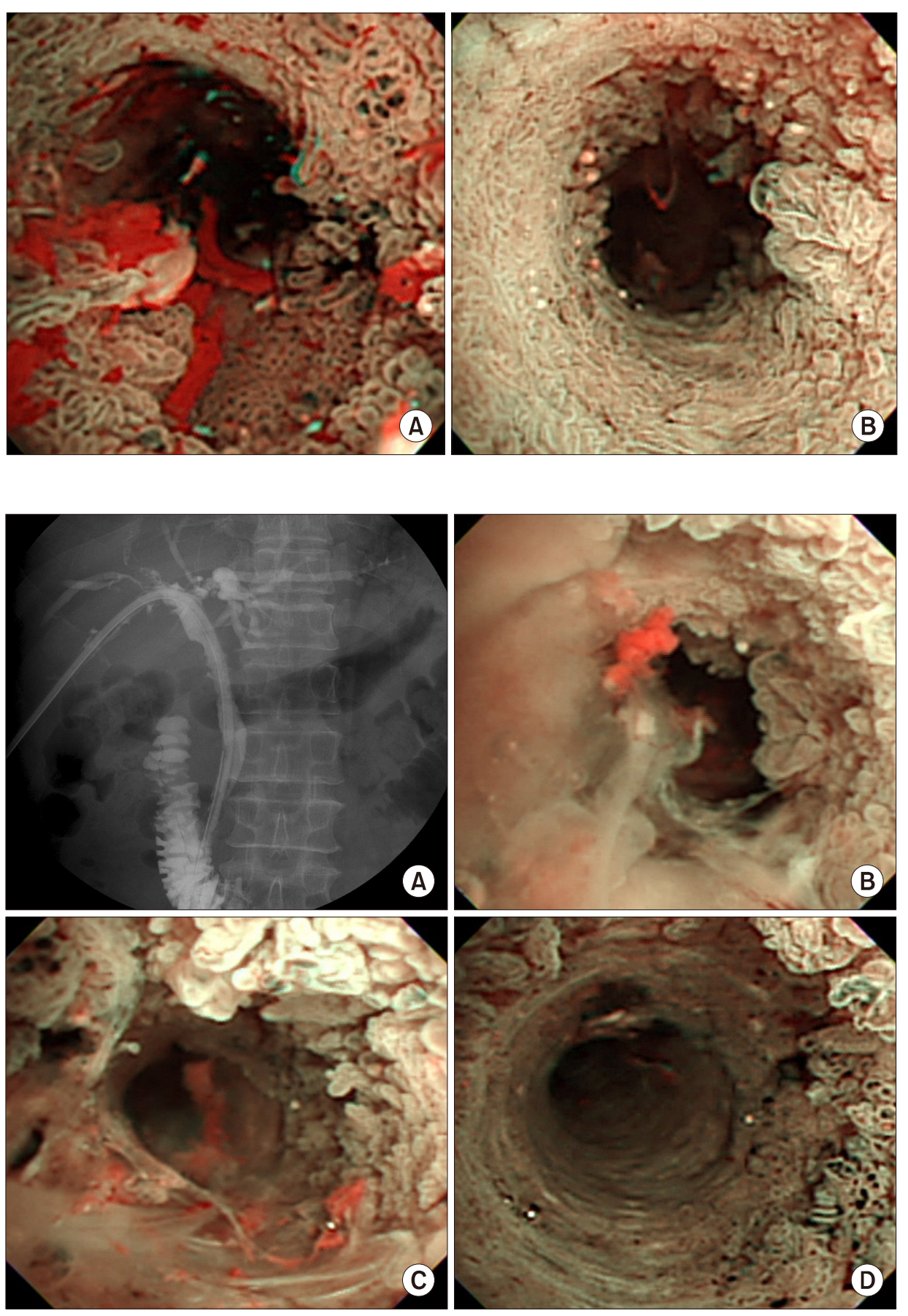

Fig. 3. Cholangioscopic findings. (A) The lumens of the whole intrahepatic ducts were covered with villotubular adenomas with focal high-grade dysplasia. (B) There were areas showing atypical villous proliferation, which was consistent with well-differentiated adenocarcinoma.
Fig. 4. Photodynamic therapy. Transcatheter photodynamic therapy was performed (A) to the intrahepatic biliary papillomatosis areas (B-D). parenchyma; positive lymphovascular invasion; no perineural invasion; and disease-free bile duct resection margin (Fig. 6).

Although the distal bile duct resection margin was free of tumor, the risk of tumor recurrence at the remnant intrahepatic bile duct still remained. Therefore, staged pylorus-preserving pancreatoduodenectomy was planned.

However, at 3 month posttransplant, the patient was readmitted due to extensive retropancreatic abscess of un- known cause (Fig. 7A). The retropancreatic abscess was barely resolved for 2 months despite percutaneous pigtail drainage (Fig. 7B). Since we did not identify the cause of retropancreatic abscess and acute appendicitis was suspected on follow-up CT scan, exploratory laparotomy was performed (Fig. 7C). We could not find any abnormality causing persistent abscess as the appendix remained normal, thus multiple abdominal drains were inserted at the abscess site. Thereafter, the patient improved gradually 


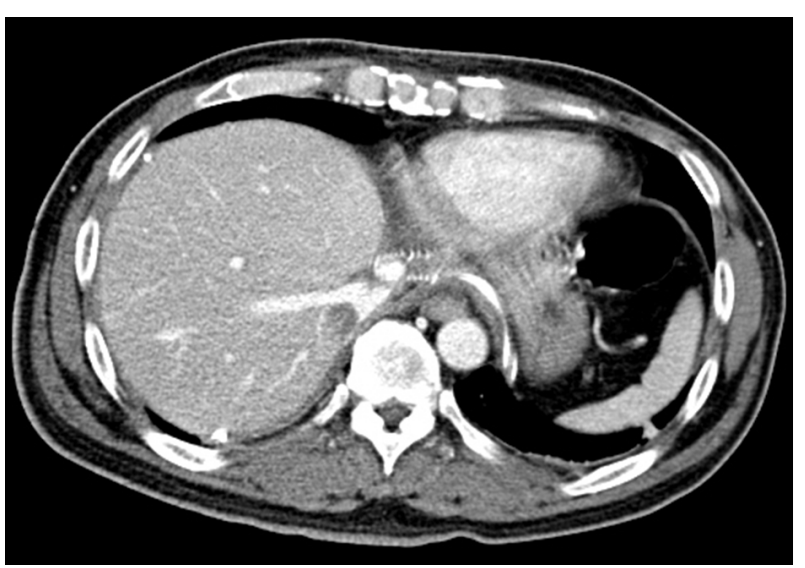

Fig. 5. Dynamic computed tomography scan taken 2 weeks after living donor liver transplantation. It was a typical posttransplant finding using a modified right liver graft. and was discharged at 8 months posttransplant. Due to late development of retropancreatic abscess and its slow recovery, we did not consider staged pylorus-preserving pancreatoduodenectomy any longer. The patient recovered complete at 1 year posttransplant without any evidence of disease recurrence (Fig. 8).

However, at 5 years posttransplant, a lung nodule was identified at the left upper lobe during routine follow-up chest CT scan, which was proven to be metastatic carcinoma on CT-guided core biopsy (Fig. 9A). Pulmonary metastasectomy was performed, in which the nodule was a 1.5 cm-sized well differentiated adenocarcinoma, compatible to metastatic lesion. One year later, a local recurrence was detected at the left upper lobe (Fig. 9B), which was also resected and turned to be a $1.8 \mathrm{~cm}$-sized metastatic adeno-
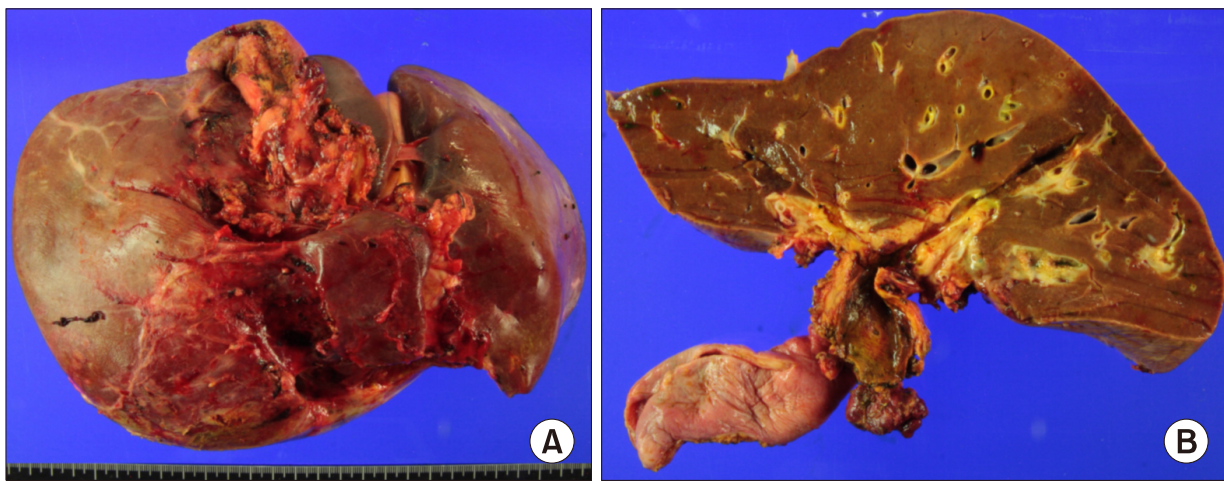

Fig. 6. Gross photographs of the explant liver. (A) No morphological change of the external contour of the liver was observed. (B) The intrahepatic ducts were lined with papillomatosis and the common bile duct was discolored by damage from precedent photodynamic therapy.
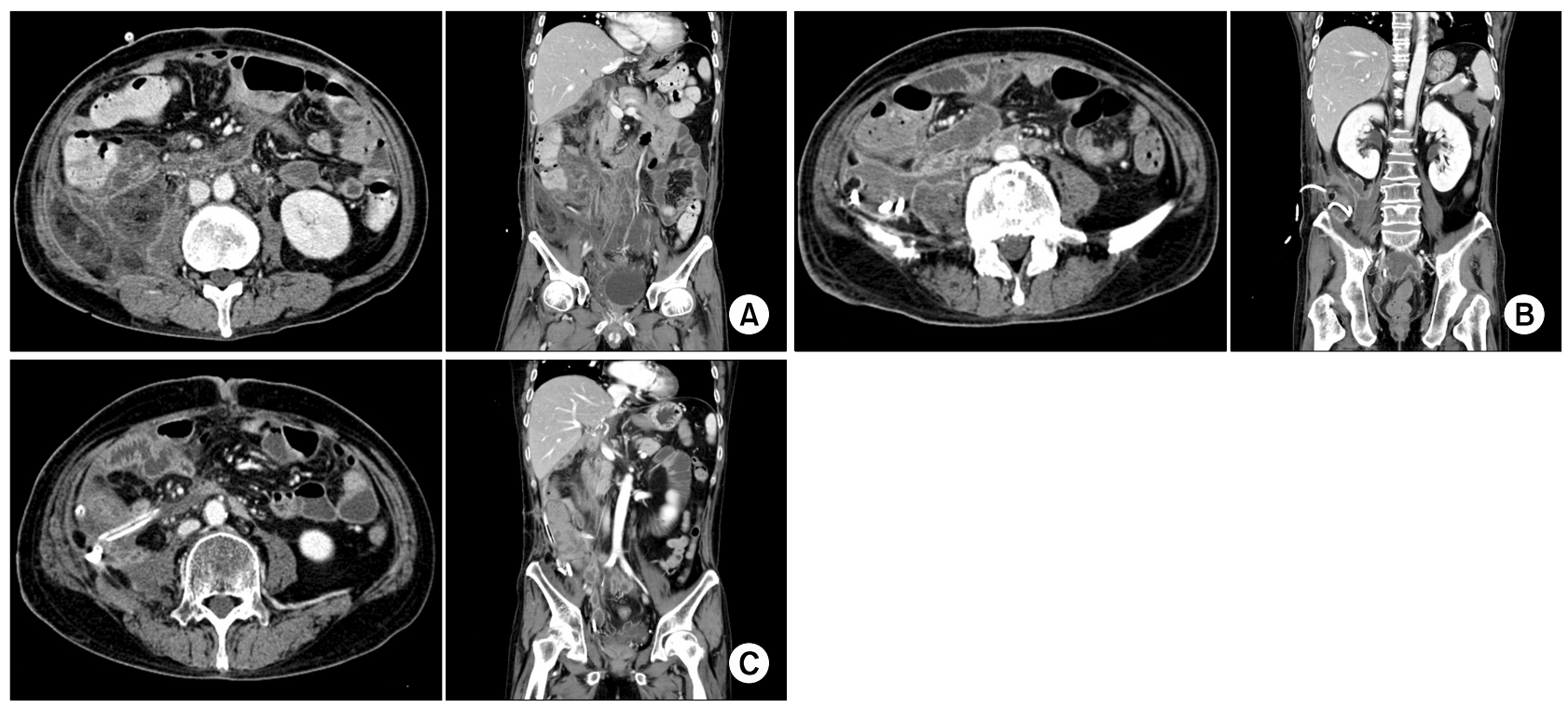

Fig. 7. Serial follow-up with computed tomography (CT) scans for retropancreatic abscess. (A) Retropancreatic abscess was first detected at the 3-month CT scan. (B) The 5-month CT scan showed slightly improvement with pigtail drainage. (C) The 7-month CT scan showed persistence of retropancreatic abscess. 

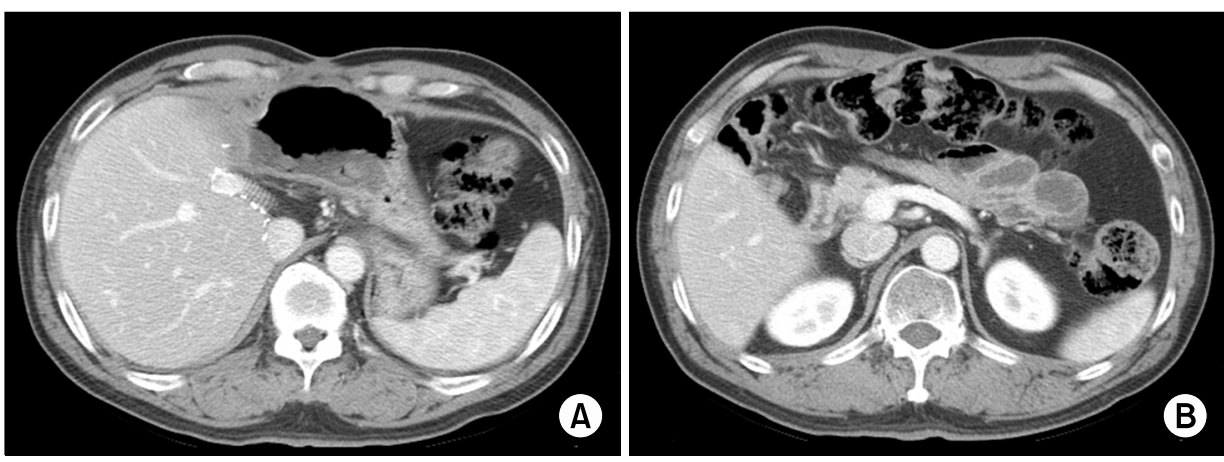

Fig. 8. Dynamic computed tomography scan taken 1 year after living donor liver transplantation. There was no abnormality at the liver graft (A) and retropancreatic abscess was completely resolved (B).
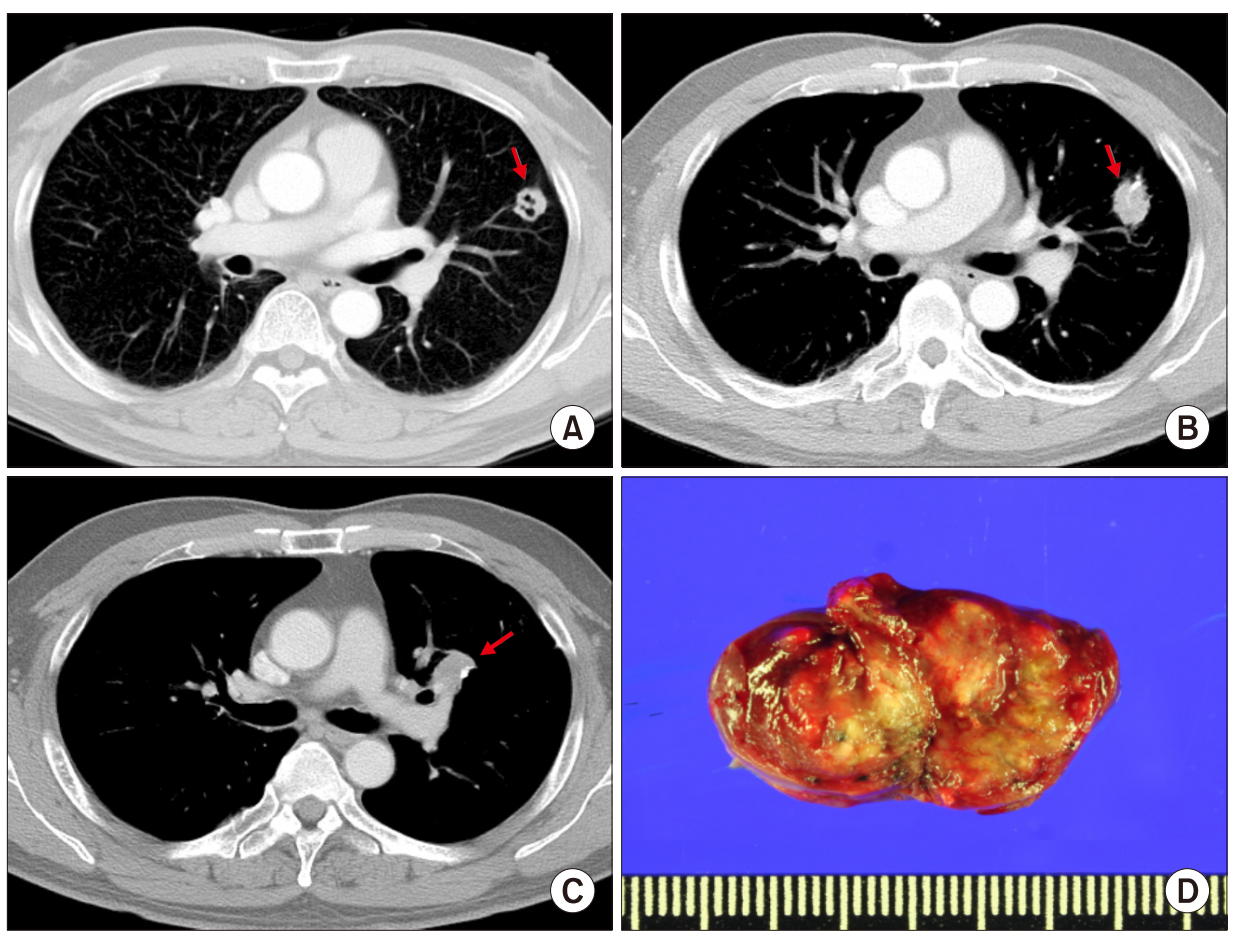

Fig. 9. Serial follow-up with computed tomography (CT) scans for lung metastasis. (A) A metastatic nodule was detected after 5 years (arrow). (B) Another metastatic nodule was detected after 6 years (arrow). (C) The other metastatic nodule was detected after 7 years (arrow). (D) Gross photograph showed the excised metastatic nodule shown at the 7-year CT scan.

carcinoma. The patient underwent adjuvant chemotherapy. However, one year later, another lung nodule was detected at the left upper lobe (Fig. 9C), which was resected again. It was proven to be a $2.5 \mathrm{~cm}$-sized metastatic adenocarcinoma (Fig. 9D). No further recurrence has developed during the recent 3 years to date. Currently, this patient is alive to date for 10 years after LDLT, despite repeated episodes of pulmonary metastasis.

\section{DISCUSSION}

Biliary papillomatosis is a rare disease of the biliary tract characterized by the presence of multiple papillary tumors in the biliary tree. According to the World Health Organization, considering the similar characteristics of biliary papillomatosis with its pancreatic counterpart, this entity has been renamed biliary intraepithelial papillary neoplasia. ${ }^{9}$

Lee et al. ${ }^{10}$ reviewed 58 cases of biliary papillomatosis and reported a malignant transformation rate of $83 \%$ in the setting of biliary adenomas. These results suggested that biliary papillomatosis should be considered as a premalignant condition with high malignant potential. The pathogenesis of progression from benign to malignant disease may follow the adenoma-carcinoma sequences. Yeung et al. ${ }^{8}$ also reported a malignant transformation rate of $42 \%$ in 78 patients, and only $55 \%$ of the patients could undergo curative resection.

The unique spreading pattern of biliary papillomatosis and the high rates of malignant transformation accounts 
for the high recurrence rates after resection. ${ }^{4,5,10}$ Considering these features, the only curative treatment is removal of the whole biliary tree, which can be achieved through liver transplantation and pancreatoduodenectomy. In the present case, some of the distal bile duct was involved and the extrapancreatic bile duct was resected during the LDLT operation. In addition, staged pancreatoduodenectomy was planned to remove the remnant intrapancreatic duct completely, however, it was not performed due to late development of retropancreatic abscess. To our knowledge, the present case was the first case of LDLT for biliary papillomatosis.

There was a case report of deceased donor liver transplantation performed to a patient with biliary papillomatosis who survived for 10 years. ${ }^{11}$ In this patient, there was no sign of involvement of the distal part of the common bile duct, hence pancreatoduodenectomy was not performed. During follow-up, at 3 years posttransplant, CT scan showed enlargement of the pancreatic head due to suspected local recurrence. Although suspicious tumor recurrence developed, the patient did not undergo pancreatoduodenectomy because the liver graft had recurrent fibrosis. During follow-up, the lesion of the pancreatic head had slightly grown, however, there was no definite evidence of recurrent disease for 10 years. ${ }^{11}$ In contrast, it was also reported that one patient underwent total pancreatectomy and liver transplantation sequentially without evidence of malignant transformation, but after 2 years biliary adenocarcinoma developed at the liver graft. ${ }^{12}$ Vibert et al. ${ }^{13}$ reported a series of three cases and concluded that in the absence of invasive carcinoma and positive lymph nodes, LT can be successfully performed.

In the present case, the underlying cause of retropancreatic abscess was unknown. We only presumed that late development of retropancreatic abscess might be associated with tissue damage from the precedent photodynamic therapy. So far, photodynamic therapy has a limited role in treating biliary papillomatosis and biliary cancers. $^{14,15}$

Experience on our case and literature review suggest that patients with biliary papillomatosis with or without malignant transformation are selectively indicated for liver transplantation. Concurrent pancreatoduodenectomy may be also indicated if the distal bile duct is involved.

\section{CONFLICT OF INTEREST}

No potential financial conflicts or other conflicts of interest exist for any of the authors of this article.

\section{ORCID}

Jin Uk Choi: https://orcid.org/0000-0001-8078-0593

Shin Hwang: https://orcid.org/0000-0002-9045-2531

Dong-Hwan Jung: https://orcid.org/0000-0001-5984-023X

Gil-Chun Park: https://orcid.org/0000-0003-1631-3258

Chul-Soo Ahn: https://orcid.org/0000-0002-3844-3646

Ki-Hun Kim: https://orcid.org/0000-0002-4016-0995

Deok-Bog Moon: https://orcid.org/0000-0002-8209-3540

Tae-Yong Ha: https://orcid.org/0000-0001-9932-0212

Gi-Won Song: https://orcid.org/0000-0002-4235-0434

Sung-Gyu Lee: https://orcid.org/0000-0001-9161-3491

\section{AUTHOR CONTRIBUTIONS}

Conceptualization: SH. Data curation: JUC, DHJ, GCP, CSA, KHK, DBM, TYH, GWS, SGL. Visualization: SH, DHJ. Writing - original draft: SH, JUC. Writing - review \& editing: SH.

\section{REFERENCES}

1. Chappet V. Cancer epithelial primitif du canal cholédoque. Lyon Med 1894;76:145-157.

2. Gu C, Lin YE, Jin H, Jian Z. Biliary papillomatosis with malignant transformation: a case report and review of the literature. Oncol Lett 2015;10:3315-3317.

3. Imvrios G, Papanikolaou V, Lalountas M, Patsiaoura K, Giakoustidis D, Fouzas I, et al. Papillomatosis of intra- and extrahepatic biliary tree: successful treatment with liver transplantation. Liver Transpl 2007;13:1045-1048.

4. White AD, Young AL, Verbeke C, Brannan R, Smith A, Prasad KR. Biliary papillomatosis in three Caucasian patients in a Western centre. Eur J Surg Oncol 2012;38:181-184.

5. Vassiliou I, Kairi-Vassilatou E, Marinis A, Theodosopoulos T, Arkadopoulos N, Smyrniotis V. Malignant potential of intrahepatic biliary papillomatosis: a case report and review of the literature. World J Surg Oncol 2006;4:71.

6. Li Z, Gao C, Zhang X, He Z, Abm K, Biswas S, et al. Intrahepatic biliary papillomatosis associated with malignant transformation: report of two cases and review of the literature. Int J Clin Exp Med 2015;8:21802-21806.

7. Cheng MS, AhChong AK, Mak KL, Yip AW. Case report: two cases of biliary papillomatosis with unusual associations. J Gastroenterol Hepatol 1999;14:464-467.

8. Yeung YP, AhChong K, Chung CK, Chun AY. Biliary papillomatosis: report of seven cases and review of English literature. 
J Hepatobiliary Pancreat Surg 2003;10:390-395.

9. Bedossa P, Paradis V. Tumors of the liver: pathologic aspects. In: Jarnagin WR, Belghiti J, Büchler MW, Chapman WC, D'Angelica MI, DeMatteo RP, et al. eds. Blumgart's surgery of the liver, biliary tract, and pancreas. 5th ed. Philadelphia: Elsevier Saunders, 2012:1223-1249.

10. Lee SS, Kim MH, Lee SK, Jang SJ, Song MH, Kim KP, et al. Clinicopathologic review of 58 patients with biliary papillomatosis. Cancer 2004;100:783-793.

11. Ferraro D, Levi Sandri GB, Vennarecci G, Santoro R, Colasanti M, Meniconi RL, et al. Successful orthotopic liver transplant for diffuse biliary papillomatosis with malignant transformation: a case report with long-term follow-up. Exp Clin Transplant 2019;17:835-837.

12. Caso Maestro Ó, Justo Alonso I, Rodríguez Gil Y, Marcacuzco
Quinto A, Calvo Pulido J, Jiménez Romero C. Tumor recurrence after liver transplantation for diffuse biliary papillomatosis in the absence of invasive carcinoma. Rev Esp Enferm Dig 2018;110: 526-528.

13. Vibert E, Dokmak S, Belghiti J. Surgical strategy of biliary papillomatosis in Western countries. J Hepatobiliary Pancreat Sci 2010;17:241-245.

14. Bechmann LP, Hilgard P, Frilling A, Schumacher B, Baba HA, Gerken G, et al. Successful photodynamic therapy for biliary papillomatosis: a case report. World J Gastroenterol 2008;14: 4234-4237.

15. Cheong CO, Lim JH, Park JS, Park SW, Kim HK, Kim KS. Volume-reserving surgery after photodynamic therapy for biliary papillomatosis: a case report. Korean J Gastroenterol 2015;66: $55-58$. 